\title{
HISTÓRIA DA CIÊNCIA X APRENDIZAGEM: ALGUMAS SEMELHANÇAS DETECTADAS A PARTIR DE UM ESTUDOO PSICOGENÉTICO SOBRE AS IDÉIAS QUE EVOLUEM PARA A NOÇÃO DE CAMPO DE FORÇA
}

\author{
NARDI, R. \\ Centro de Ciências Exatas. Departamento de Física. Universidad Estadual de Londrina. \\ Paranà. Brasil.
}

\begin{abstract}
SUMMARY
In this article, based upon a psychogenetic study on the ideas which evolve to the concept of field of force, we show some students' conceptions which seem to be similar to others found in the History of Science. We analyse aspects which could contribute to the construction of the teaching of this concept.
\end{abstract}

\section{INTRODUÇÃO}

Em recente pesquisa realizada sobre as idéias que evoluem para a noção de campo de força, Nardi (1990) fornece uma série de subsídios visando a construção do ensino desse conceito.

Neste artigo procuramos descrever resumidamente 0 estudo efetuado e destacar um dos pontos nele evidenciado: a semelhança entre certas noções apresentadas pelos estudantes e aquelas registradas no decorrer da evolução histórica que culminaram com a aparição do conceito, analisando aspectos que podem contribuir para possíveis mudanças conceituais.

\section{O ESTUDO REALIZADO}

Este chamado «estudo psicogenético» analisou numa amostra de 45 individuos escolhidos aleatoriamente entre estudantes de 6 a 17 anos de idade' da Escola de Aplicação da Faculdade de Educação da Universidade de São Paulo, como evoluem nestes as noções com o decorrer da idade, ou seja, como os alunos constroem as principais características ou propriedades da noção de campo de força.

$O$ instrumento de pesquisa utilizado foi a entrevista clínica através do método clínico ou método de explo- ração crítica, do tipo empregado por Piaget e seus colaboradores nos estudos do desenvolvimento cognitivo da crianca. Estas entrevistas, de duração média de $30 \mathrm{minu}$ tos, foram gravadas em videotape e foram desencadeađas a partir de quatro experimentos básicos que foram selecionados levando em consideração aspectos do campo magnético, do campo elétrico e do campo gravitacional. Esses experimentos utilizados eram constituídos de materiais simples como ímãs e objetos metálicos $\left(1^{2}\right.$ situação), imãs com limalha đe ferro $\left(2^{2}\right.$ situação), pêndulo elétrico ( $3^{a}$ situação) e um diapositivo onde se mostrava um astronauta no espaco ( $4^{2}$ situação). Numa parte integradora final o entrevistador, através do questionamento, tenta integrar as respostas dadas pelo aluno, verificando assim se o entrevistado percebe as características comuns entre as diversas situações desencadeadoras, isto é, se ele consegue generalizar as situaçōes numa só explicação causal $\rightarrow$ modelo de campo de força, ou em outro modelo que ele possa ter.

O levantamento dos dados das entrevistas clínicas permitiram tambem verificar nos sujeitos a evolução da concep̧̧ăo de Terra como corpo cósmico; a semelhança entre os modelos apresentados pelos sujeitos e os modelos apresentados na evolução histórica do conceito; a evolução do léxico científico e a influência do modelo de campo de força passada pela televisso aos sujeitos através de desenhos animados. Destacaremos aqui exemplos de 
semelhanças detectadas entre modelos apresentados pelos alunos e os ocorridos na História da Ciência, visando subsidiar o ensino do conceito de campo de força.

\section{AS SEMELHANÇAS ENCONTRADAS}

A partir da análise das respostas dadas pelos sujeitos nas entrevistas, pudemos encontrar uma série de semelhanças entre as idéias ou modelos apresentados pelos sujeitos e os registrados ao longo da história da evolução das idéias que culminaram com o conceito de campo. Estas constatações, conforme prevêem Piaget e Garcia em Psicogênese e História da Ciência (1987), aparecem mesmo em termos de conteúdos, geralmente na fase por eles chamada de "pré-cientifica». Destacaremos aqui algumas das idéias dos sujeitos e suas semelhanças com os modelos históricos.

Platão ( $428 \mathrm{aC}-347 \mathrm{aC}$ ), por exemplo, explicava a atração do âmbar atritado como uma espécie de aspiração semelhante à produzida por um organismo vivo (Schurmann 1937, Cajori 1938).

Alguns sujeitos da amostra referem-se à atração exercida pelo ímã como algo semelhante. Ao usar expressōes como «sugar» ou "alimentar» para designar «atrair», passam idéias semclhantes. As explicações de TIA, EDI e RAF ilustram bem essas semelhanças.

TIA $(8: 3)^{2}$ - O que está acontecendo aŕ? (O aluno aproxirna o ímã da limalha e esta "gruda» toda no ímã) - Ah... ele está sugando. - Ele suga em todos os pontos? - Suga. Por que, hein? - Porque ele tem a colinha especial para todos os pontos dele... olha só que tá totalmente cheio! (a limalha gruda toda no ímã) -

EDI (9:8) - Eu não sei explicar... (toma o f́mã nas mãos e põe sobre a limalha. A limalha é então toda atraída pelo ímã) - O que esta acontecendo aí? - Ele (o ímã) tá puxando todo o ferro. - Por que será que ele puxa, hein? - Prá se alimentar. - Ah... ele está se alimentando? - (Faz sinal de sim com a cabeça). - E cle se alimenta do que? - Da potência do ferro. - Como que ele se alimenta? - Não sei... do ferro e da potência do ferro... prá cle ficar com mais força... quer ver? «... (vai passando o ímã sobre a limalha e cada vez vai acumulando mais limalha no ímã). - $\mathfrak{E}$ aqui no preguinho... quando eu tento o preguinho, quando o ́mã puxa o preguinho... ele está se alimentando, támbém? - Não. - Aqui não está e lá está? Como é isso? - Porque lá tá picado e tá mais solto (a limalha) e aqui ele tem que ficar bastante tempo prá tirar. - Como ficar bastante tempo? - Aqui (na timalha) ele tá picado então... a radiação fica mais fácil dele tirar; mas aqui (no ímã com o preguinho), cle está preso. - E lá, tem radiação? Sim. - O que é essa radiação? - Do ferro... - O ferro tem radiação?.. - ou é o ímã que tem? - O ímā. E alimenta do ferro... o ímã fica mais potente... - Mas como que ele se alimenta? Me diga. - Grudando... aí ele vai tirando, tirando... aí ele fica mais forte. -

RAF (10:1) - Quando eu tenho o ímã (mostra) ele puxa oclips, né? Como que ele puxa de longe? - Parece que ele tá sugando assim... (imita fazendo barulho com at boca).. daí ele puxa e gruda. - Ele suga, então? - parece, né? suga como? -...

A produção de correntes de ar ao se atrair os corpos (Plutarco) e a formação de redemoinhos (Lucrécio) responsáveis pela atraçẳo dos corpos leves aparece também nas explicaçōes dos sujeitos na forma de «ventinhos», «garrinhas» e assemelhados.

Embora a presenca do «ventinho» seja mais comum, os exemplos abaixo exemplificam bem está semelhanças:

DEB (9:3) - Onde está a força? - Em nenhum lugar. Ela saiu... - Não está aqui? (no ímã) - Tá - Mas eu não vejo!... - Só se colocar aí (na limalha) que ele puxa. - Fi como que ele puxa? Por que você acha que o ímã puxa? - Porque tudo que vem perto ele... ele vai... ele puxa com a força dele que ele tem... - E como que ele puxa, hein? - Acho que é um ventinho que tem força... é que eu nunca mexi... - F onde está este ventinho aí? - Tá dentro dele (do ímã) e quando algum ferro vem assim perto, o ventinho puxa. - O ventinho sai dele entäo, e puxa? - Quando tem alguma coisa do lado dele, o ventinho sai de dentro e puxa. -

FEL (7:8) - Então tá... e como que gruda hein? Tá vendo, eu solto o preguinho de longe e ele gruda... por exemplo aquela cadeira, sc eu quiser pegá-la, ela não gruda de longe, né? - (Balança a cabeca afirmativamente). - E como que aqui ele pega? Como ele faz? - (Está pensativo, não responde, demonstra não saber). - (Mostra mais uma vez) Como que faz? - Acho que solta um vento e puxat ele prá lá. (gesticula) - Acha que solta um vento? E solta onde? - Aqui. (aponta) - Aqui também solta? (aponta) (balanca a cabeca afirmativamente) Solta. - E onde está esse vento? - Aqui dentro. (aponta o ímã) -

FEN (11:3) - Tem uma outra ... como uma... como cola... ele puxa e gruda. Não sei explicar... - Como você acha que é isso, mais ou menos... explica-me com outras palavras... de qualquer jeito... -... por exemplo... assim... um raio que ele transmite que vai puxar oferro e que o ferro vai ficar também outro ímã... vai também conter... - E de onde sai esse raio? - Do ímã... - Aqui assim? (aponta num certo ponto do ímã) - Sai. - Aqui sai? (num outro ponto do fmã) - Sai. - Como que e isso? -... . Onde tem raios aqui, nesse? (aponta para o ímã sob o papel com limalha - Aqui (gesticula fazendo um círculo em torno do ímā) em volta daqui. - E esse raio... ele transmite esse raio... - que vai puxar o ferro. - Fntăo é assim?... O ímã transmite esses raios em todos os pontos? - Em todos os pontos dele (gesticula fazendo círculos em torno đo ímã) ... porque não e só uma ponta que cle vai puxar... pode ser em várias.

ATA (15:2) - Por que gruda? - Porque... eu achei uma teoria né?... assim... quando a gente atrita um canudo, aparece assim... tipo garrinhas, que gruda no alumínio, tira toda a energia. - E onde que aparece essas garrinhas aqui? (no canudo) - É; no canudo. - E como que é essa teoria que você falou? a garrinha que está puxando? A gente não enxerga essa garrinha? - Não, não enxerga. E o que que a garrinha faz; ela vai lá... - E puxa. Depende; também, não é toda vez; às vezes, repele; às vezes atrai... 
- E quando repele? - Quando repele?... sei lá... acho que não deu prá catar direito, então, e a energia não passa para o canudo.

As idéias expressas por Fracastoro em seu De sympathia et antipathia rerum que explicam a «atração mútua do tgual pelo igual" e combatida por Gilbert (1600), também aparecem em alguns sujeitos:

GUI (7:10) - Onde ele puxa, entâo? - No meio e dos dois lados. - E se não tivesse o clips, ele puxa tambérn? - Não. - Por que? - Porque não tem outra coisa igual a dele. - E se fosse outro material á́... esse preguinho? Também puxa? - Puxa. Porque é đo mesmo material do clips. - Por que você acha que puxa? - Eu não sei... - Por que que o ímã puxa? - Porque é metal... igual à coisa dele... «... (aproxima o prego do ímã e este o atrai) - Igual a que? $\mathrm{A}$ isso que ele tem. (refere-se ao material do ímã) -

PAI (13:1) - Ah... devido a forças, né?... propriedades que o ímã tem, de atrair diversos materiais. - E como que são essas forças? - Eu acho que... deixa ver... talvez essas propriedades que o ferro tem, e certos minerais, fattam proímã, né, e se encaixam, entendeu? Não sei exatamente... - Então, você acha que ele procura assim... alguma coisa que falta? - É; mais ou menos isso.

THA (8:6) - Por que você acha que gruda? - Por que esse é igual a esse - Como assim, igual? - Não é igual de formato, né... mas o produto dele é igual. - E esse daqui? (prego) - igual a esse e esse (refere-se ao ímã e ao clips). E igual porque também gruda. - Esse também gruda? (clips) - Não; só esse. (mostra o ímã) - E se eu aproximo esse? (prego) - Ele val puxar e vai tremer. - E se eu vir com ele aqui? (em outra posição) - Vai puxar. - E se eu vir aqui em cima (vem com o clips de cima) vai grudar também? - Acho que não. - (Solta) Grưou? - (balanca a cabeca afirmativamente e sorri). - Por que você acha que acontece isso, hein? - Porque eu acho que esse (prego) é igual a esse (ímã); mas não de formato. - Humm... do mesmo material? - É. -

Os «effluvia» de Gilbert, despertados pelo calor gerado na friç̧ão dos «corpos elétricos" também aparecem, como mostram os trechos de entrevistas abaixo:

MAR (9:I) - Deixa eu ver uma coisa... (testa se o canudo é atraído pelo ímã e descobre que não)... ah, não pega... Ah, não tem graça... (sorri) - Otha, isso aqui não pega, (mostra um canudo sem ser atritado e aproximando do metalzinho)- Por que? - Porque você não raspou ali. (no canudo) - Então eu vou raspar... pega? - Pegou. - E como você acha que pega? O que tá acontecendo aqui? - Acho que é quando ele esquenta...ele num... fica tipo de um ímã, que eu não sei explicar... - Esse coisinho aqui... o canudimho... ela pega de longe, né? Ele pega sem encostar também, né? - Como assim? - Esse coisinho aqui... o canudinho, pega de longe? - Pega. - Como você acha que é...? - E esse não pega daqui (refere-se ao imä), daqui assim... já vai pegando, $\delta »$. - E do mesmo tipo então? Não do mesmo tipo; semelhante. - Me diga uma coisa; 0 que acontece aqui? - Não pega. - Eu vou aproximar... Ele vai fugindo. - Por que vai acontecendo isso? - Não sei, não sei explicar isso. - Mas o que você acha que está acontecendo aqui? - Não sei... ele vai fugindo porque eu acho que vai encalorando. - Qual vai encalorando, ele? (refere-se ao metalzinho) - Vai encalorando ele. - Esse aqui. o canudo? - É ; este (canudo) vai encalorando este (metal). Quando ele, (o canudo) perde o calor, ele já não pega ele... -

ANA (10:8) - O canudinho que atrai? - Não...é... pode ser o canudo, qualquer coisa... - Mas aqui; o que atraiu aqui, foi o canudo? - Foi o canudo que tá quente. - E o que acontece; como e isso? Como ele atrai? - É que a gente... ele tá quente... por causa que o plástico, ele atrai, assim... quando tá quente... papel, assim... -

FEN (11:3) - Eu vou fazer isso: vou pegar um canudinho qualquer e vou esfregar aqui e vou fazer isso (aproximar do metalzinho). O que será que é isso? - Um ímã. - Um ímã, também? - E... pode ser, porque conforme você esfregou, ele esquentou... como isso aqui é um metal, ele vai puxar. - Então, é tipo de um ímã, também? - Também. - Você disse que lá no imã tinha aqueles pontos... aqui no canudo, também têm? - Onde você esfregou... na parte que você esfregou... que ele esquentou... - Isso é por que esquenta? - Pode ser, também... tem os meninos na rua, que eles pegam e comecam a bater um pedaço de ferro no outro... e fica... - Aqui também ficou um ímä, então? Ficoul. -

Outro exemplo de semelhanças é o caso de SER (14:6), cujo modelo de campo gravitacional é semelhante ao modelo de Gilbert (orbis virtutis).

Ao exemplificar a atração de um corpo pela Terra, SER assim se expressa:

SER (14:6) - Porque ... ela solta as partículas... o centro da Terra solta partículas prá tudo quanto é lado... ela bate no corpo... e atrai... - E puxa o corpo? - Isso. - E isso... prá todos os lados da terra? Em todos os pontos? - E; prá todos os pontos. - Como que é a coisa?... eu solto uma pedra; ela cai... e se eu solto mais de cima? - Depende do limite da força de atração. - E na Terra, onde é esse limite? - Eu acho que é a atmosfera. - Saiu da atmosfera... - Eu acho que fica sem, já. -

\section{Figura 1}

A «Orbis Virtutis» de Gilbert (Fonte: Gilbert, 1600, op.cit., p.122) l PMT 100\%

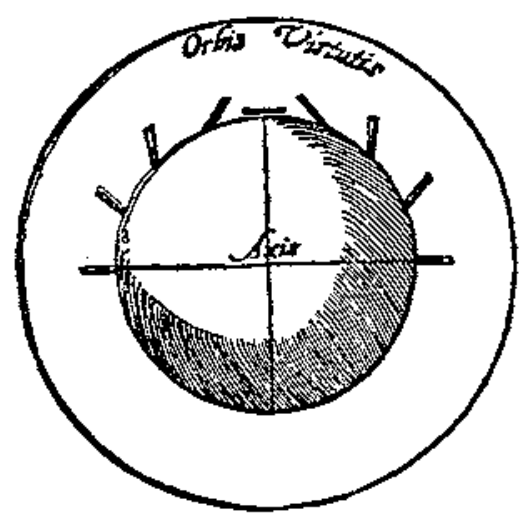


Para representar o planeta Terra, os desenhos dos sujeitos que apresentam este modelo semelhante ao "orbis virtutis» de Gilbert (1600), como SER, geralmente relacionam esse «limite», como eles chamam, à atmosfera.

Estes desenhos confirmam essa semelhanças:

Figura 2

Copias dos desenhos (reprodução reduzida) de SAN (10:3), $4^{A}$ série (alto à esquerda), de FER (12:3), $6^{\text {* }}$ série, (alto à direita) e de LEA

(l 1:8), $6^{2}$ série (abaixo). Observa-se em todos os desenhos o "limite" de atraçäo gravitacional semelhante to "orbis virtutis" de Gilbert. No desenho dc SAN aparece um «astronauta no espaço». Nos desenhos de FER e LEA aparece também «a lua».

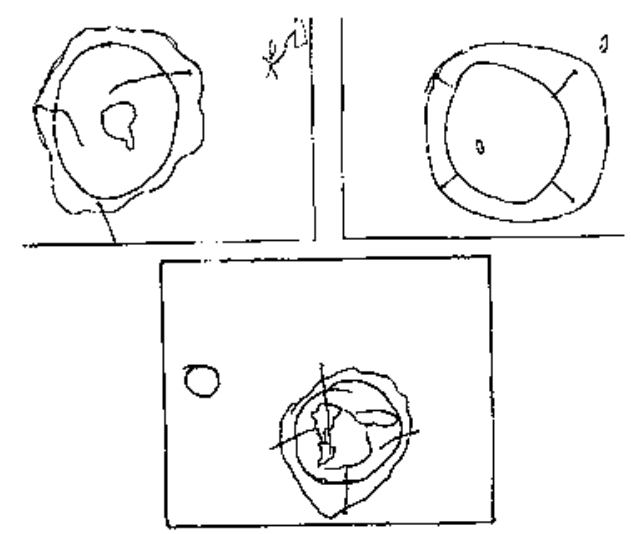

A idéia principal dos modelos apresentada por estes alunos é que a atraçāo tem um limite que coincide com o fím da atmosfera. Se o corpo está dentro deste limite, ele é atraído; caso contrário, fica «flutuando» no espaço ou é atraído para outro planeta, por exemplo.

\section{DA IMPORTÂNCIA DE SE CONSIDERAR ESTES DADOS NA CONSTRUÇAOO DO ENSINO DO CONCEITO}

A nosso ver, a construção de um conhecimento a partir de dados imediatos da experiencia, como acontece na relação entre o sujeito cognoscente e o objeto do conhecimento na psicogênese, parece mais «legítima» ou "pura» (ou seja, menos impregnada de influências extemas como na História da Ciência), que a relação entre o cientista $e$ o objeto do conhecimento, por entendermos esta última como uma construção de saber a partir de um saber já socializado.

A crianca, segundo a teoria piagetiana, vai construindo e aprimorando seu "equipamento operatório» que percebe o objeto do conhecimento tanto mais complexo ou elaborado quanto mais se aprimora, isto $\hat{E}$, as relaçōes sujeito-objeto são mútuas, nos dois sentidos, um modificando concomitantemente $o$ outro.

A evolução da crianca ocorre num processo semelhante. Entretanto, na relação sujeito/objeto, ou entre o cientista e a Ciência, a componente social, exógena, por ser um saber acumulado de várias fontes $\mathrm{c}$ sujeita a condicionantes cconômico-sociais, parece-nos muito mais complexa do que o objeto presente na relação sujeito/objeto da psicogênese.

Embora a analogia acima seja relativa, entendemos que a evolução histórica encerra se não a mesma, uma importância pelo menos significativa como subsídio para reflexão do processo da aprendizagem escolar e conseqüente construção do ensino.

Uma das abordagens que se da à História da Ciência e sua utilização na deteç̧ão de obstáculos derivados da evolução do sistema cognitivo do aluno, os chamados «obstáculos epistemológicos».

Ao encararmos a aprendizagem como um processo de construção de conhecimentos $e$ a evolução histórica também como descrição de evoluçăo de conhecimentos, entendemos ser possível extrair desta elementos importantes que possam ser utilizados na análise daquela. Entretanto, «isto nảo significa postular um «paralelismon entre a História da Ciência e o desenvolvimento da inteligência e do conhecimento individual», isto é, «...o aluno atual vive, pensa, constrói seus conhecimentos em uma sociedade diferente da qual se produziram os conhecimentos que se deve reproduzir em sala de aula» (Gagliardi 1988, p. 293).

Embora discordando de Gagliardi quando se refere a «reproduzir» conhecimentos em sala de aula, o que nos parece plausível é analisar na leitura da evolução dos fatos históricos passos importantes que possam subsidiar a leitura da evolução dos conhecimentos no indivíduo - a aprendizagem. Acreditamos que, mesmo não utilizando a reprodução histórica como metodologia de ensino, como o fazem os adeptos do metodo da redescoberta como Raichvarg (1987), Gohau (1987) e outros, só o fato de conhecer os obstáculos históricos jáá bastante importante em termos de exemplos decorrentes de situações eventuais numa construção de conhecimentos.

Uma outra abordagem decorrente da primeira citada, é a utilização da História da Ciência para definir os conteúdos dos cursos. Gagliardi, por exemplo, propöe que se centrem cursos nos conceitos estruturados, ou seja, nos "conceitos que uma vez construídos pelo aluno determinam uma transformação de seu sistema conceitual, que permite continuar com a aprendizagem” (Gagliardi 1986, p. 293).

Entende que a História da Ciência permite visualizar, por exemplo, os conceitos estruturantes de uma teoria, a elaboração de novos conceitos e teorias, bem como a utilização de novos métodos de investigação c novos instrumentos conceituais, pressupondo assim uma evoluçâo da ciência como resultado de transformaçôes cstruturais, como as sugeridas por Kuhn (1975) ao analisar o que chama de «estrutura das revoluçôes cientificas».

Num outro tipo de análise, Piaget e García (1987) relacionam a gênese do conhecimento na crianca com a evoluçāo histórica das idéias científicas. No caso específico da evolução da Física de Aristóteles à Mecânica 
do «impetus», estabelecem correspondências entre as quatro fases históricas na Ciência (os dois motores aristotélicos, o recurso a um único motor externo, a descoberta do «impetus» e a descoberta da aceleração) com as quatro etapas da psicogênese. As correspondências desse tipo levaram Piaget e Garcia à conclusão de que «o paralelismo entre a evolução das noções no decorrer da história e no seio do desenvolvimento psicogenctico refere-se ao proprio conteúdo das noções sucessivas», considerando isto coerente por se tratar de conceitos «de algum modo pré-científicos».

Eles, entretanto, consideram «absurdo procurar generalizar um tal paralelismo de conteúdo no caso das teorias propriamente cientificas, como as que surgiram entre a mecânica newtoniana e a relatividade einsteniana) (Piaget e Garcia, 1987, p. 38). Consideram importante, entretanto, tornar claro que o objetivo que procuram atingir «não é de mođo algum estabelecer correspondência entre as sucessões de natureza histórica com as que revelarn as análises psicogenéticas, sublinhando os conteúdos, mas, oque completamente diferente, mostrar que os mecanismos de passagem de um período histórico ao seguinte são análogos aos da passagem de um estágio psicogenético ao seu sucessorn (Piaget e García, 1987, p. 39).

Ressalvadas as diferencas entre os dois tipos de construção, a psicogenética e a histórica, o que se observa é que realmente muitas vezes oaluno apresenta jdéias semelhantes às obsevadas no decorrer da História como, por exermplo, as constatadas por Clement (1982), Whitaker (1983), Driver (1985) e Saltiel e Viennot (1985) que compararam as concepções espontâneas de alunos com idéias de Galileu, Aristóteles e outros fílósofos.

Wandersee (1986), por exemplo, parte da História da Ciência para mostrar as relações entre as dificuldades conceituais dos alunos sobre o conceito de fotossíntese e a transformaçäo do conceito através dos tempos na visão de historiadores da Ciência. Conclui que a história desse conceito pode auxiliar os educadores na antecipação de concepções errôneas (misconceptions) dos estudantes.

De maneira idêntica, Casadella e Bibiloni (1985) mostram certo paralelismo entre os erros conceituais que aparecem durante a aprendizagem do conceito de força centrípeta e a construção histórica desse conceito.

Moreno (1986) aponta um outro ponto que consideramos importante, au comparar a construção do pensamento científico com a construção do conhecimento no indíviduo: a existência do «erro». Ao discutir a importância que a Epistemologia Genética tem dado ao erro na construção intelectual, assim se expressa:

«Tanto na história das Ciências como na psicogênese do conhecimento, a inteligência não é o que produz verdade - que ninguém sabe, por outro lado, o que é - senão talvez
- que é capaz de transformar os dados do exterior ordenando-os em sistemas organizados que possuem uma coerência interna. Esta concepção está muito além do simples modelo dualista de verdadeiro-falso com reminiscências morais que provêem das noções de bem e mal» (Moreno 1986, p. 62).

De fato, ao entender a aprendizagem como um processo de construção de conhecimentos, não tem sentido ao educador utilizar-se de vel hos chavôes como certo/errado, verdadeiro/falso, melhor/pior, etc., para interpretar os supostos «erros» de aprendizagem e sim considerá-los estágios de uma evoluçảo, interpretando-os como necessários e importantes dentro do processo.

Uma série de outras aplicaçōes ou implicaçōes da História da Ciência a situações de ensino tem sido realizada como, por exemplo, para introduzir em classe discussões sobre a produçã̃o, a apropriação e o controle dos conhecimentos pela sociedade.

As consideraçōes até aqui aventadas nos levam a admitir que, da mesma maneira que podemos analisar a aprendizagem a partir de dados num estudo psicogenético, podemos também fazê-lo com a História da Ciência. É claro, entendendo-a também como instrumento de análise ou como um exemplo de processo de construção de conhecimentos. Não pretendemos, portanto, nesta análise, considerar o aluno como um simples reprodutor do caminho descrito pelos cientistas ao longo da história, mesmo porque, como afirma Moreno (1986), os cientistas não reproduziram nada previamente estipulado.

Reconhecer na História da Ciência ou na psicogênese exemplos de construção é importante para nos conscientizarmos de que a aprendizagem é algo que se processa de maneira semelhante. O importante, portanto, é «ler» nessas experiências paralelas possíveis situações com as quais poderemos defrontar-nos, ao analisar processos de construção - como a aprendizagem.

\section{NOTAS}

- A relação entre a idade dos indivíduos da amostra e o nível de escolarização destes pode ser entendida da seguinte forma: No sistema educacional brasileiro a escolarização primária, corresponde ao curso de $1^{\circ}$ Grau, é de oito anos (da primeira série do $1^{\circ} \mathrm{grau}$ - idade média de sete anos - à oitava série do $1^{\circ}$ grau - idade média de 14 anos). Já o Curso de $2^{\circ}$ Grau, equivalente ao High School nos Estados Unidos, corresponde a três anos (da primeira série do $2^{\circ}$ Grau - idade média de quinze anos - à terceira série do $2^{\circ} \mathrm{Grau}$ - idade média de dezessete anos)

2 Os números entre parênteses indicam as idades em anos e meses dos indivíduos da amostra respectivamente, por exemplo, (6:8) significa seis anos e oito meses. 


\section{REFERENCIAS BIBLIOGRÁFICAS}

CAJORI, F., 1938. A History of Physics. (The MacMillan Co: Nueva York).

CASADELLÀ, J. e BIBILONI, L., I985. La construcción histórica del concepto de fuerza centripeta en relación con las dificultades de su aprendizaje, Enseñanza de las Ciencias, $3(3)$, pp. 217-225.

CLEMENT, J., 1982. Student's Preconceptions in Introductory Mechanics, Am. J. of Physics, 50 (1), pp. 66-71.

DRIVER, R., 1985. The Pupil as a Scientist? (Open University Press: Philadelphia).

GAGLIARDI, R., 1986. Los conceptos estruturales en el aprendizaje por investigacion, Enseñanza de las Ciencias, 4 (1), pp. 30-35

GAGLIARDI, R, 1988. Cómo utilizar la historia de las ciencias en la enseñanza de las ciencias, Enseñanza de las Ciencias, 6 (3), pp. 291-296.

GILBERT, W., 1600. De Magnete. Trad. cast. 1958, Fleury Mottelay. (Dover Publication Inc: Nueva York)

GOHAU, G., 1987. Difficultes d'une pedagogie de la decouverte dans l'enseignement des sciences, Aster, 5, pp. 49-69.

KUHN, T.S., 1975. A Estrutura das Revoluçöes Cientificas. (Perspectiva: São Paulo).
MORENO, M., 1986. Ciencia y construcción del pensamiento, Enseñanza de las Ciencias, 4 (1), pp. 57-63.

NARDI, R, 1990. Um Estudo Psicogenético das idéias que evoluem para a noção de campo - Subsídios para a construção do ensino desse conceito. Tese de doutorado. Faculdade de Educação, Universidade de Sảo Paulo.

PIAGET, J. e GARCIA, R., 1987. Psicogênese e História das Ciências. Trad cast. de M.F.M.R. Jesuino. Coleção Ciência Nova, no. 6. (Publicaçōes Dom Quixote: Lisboa).

RAICHVARG, D., 1987. La didactique. A-t-elle raison de s'interesser a l'histoire des Sciences?, Aster, 5, pp. 3-34.

SALTIEL, E. e VIENNOT, L., 1985. Qué aprendemos de las semejanzas entre las ideas históricas y el razonamiento espontáneo de los estudiantes?, Enseñanza de las Ciencias, 3 (1), pp. I37-144.

SCHURMANN, P. F., 1937-1945. História de la Fisica, 2 vol. (Editorial Nova: Buenos Aires).

WANDERSEE, J.H., 1986. Can the History of Science Help Science Educators Anticipate Student's Misconceptions?, Journal of Research in Science Teaching, 23(7), pp. $581-597$.

WHITAKER, R.J., 1983. Aristotle is not dead: Students Understanding of trajectory motion, Am. J. Physics, 5 I (4), pp. $352-357$. 